\title{
Effect of green tea catechins on gastric mucosal dysplasia in insulin-gastrin mice
}

\author{
TAKASHI OHNO ${ }^{1}$, MASAHIRO OHTANI ${ }^{1}$, HIROYUKI SUTO ${ }^{1}$, MAKOTO OHTA $^{2}$, YOSHIAKI IMAMURA ${ }^{2}$, \\ HIDETAKA MATSUDA $^{1}$, KATSUSHI HIRAMATSU ${ }^{1}$, TOMOYUKI NEMOTO ${ }^{1}$ and YASUNARI NAKAMOTO $^{1}$ \\ ${ }^{1}$ Second Department of Internal Medicine, Faculty of Medical Sciences, University of Fukui, \\ Eiheiji-cho, Yoshida-gun, Fukui 910-1193; ${ }^{2}$ Division of Surgical Pathology, University of Fukui Hospital, Fukui, Japan
}

Received December 22, 2015; Accepted March 8, 2016

DOI: 10.3892/or.2016.4717

\begin{abstract}
Green tea catechins (GTCs) have been implicated in various physiological effects, including anti-carcinogenic activities. In the present study, we evaluated the effects of GTCs specifically on the development of gastritis and premalignant lesions in insulin-gastrin mice. Nine-week-old male INS-GAS mice $(n=38)$ were supplemented with GTCs for 4 and 28 weeks, and their body weights, serum gastrin levels, histopathology and pro-inflammatory cytokine levels in gastric tissue and mucosal cell proliferation were monitored. Body weights of the GTC-treated mice were significantly lower than those of the untreated controls $(\mathrm{P} \leq 0.05)$. Serum gastrin levels were suppressed at the age of 37 -weeks $(\mathrm{P} \leq 0.05)$. The histopathological scores indicated that the extent of dysplasia was significantly diminished ( $\mathrm{P} \leq 0.05)$, although GTC supplementation did not affect the inflammation scores. The messenger RNA levels of interferon (IFN)- $\gamma$ were significantly reduced at the age of 13 weeks $(\mathrm{P} \leq 0.05)$, although the changes did not reach statistical significance at the age of 37 weeks $(\mathrm{P}=0.056)$. The labeling index of Ki-67 immunohistochemistry was significantly decreased $(\mathrm{P} \leq 0.05)$. These results demonstrated that GTCs may play a protective role in the development of gastritis and pre-malignant lesions via an IFN- $\gamma$, gastrin, and mucosal cell proliferation-dependent mechanism in this rodent model and potentially in humans.
\end{abstract}

\section{Introduction}

Gastric cancer is the fourth most common cancer and the second leading cause of cancer-related mortality worldwide (1). The etiology of gastric cancer is multifactorial and includes Helicobacter pylori (HP) infection, smoking tobacco and

Correspondence to: Dr Yasunari Nakamoto, Second Department of Internal Medicine, Faculty of Medical Sciences, University of Fukui, 23-3 Matsuoka Shimoaitsuki, Eiheiji-cho, Yoshida-gun, Fukui 910-1193, Japan

E-mail: nakamoto-med2@med.u-fukui.ac.jp

Key words: catechins, INS-GAS mouse, anti-carcinogenic activity, gastric cancer, gastric mucosal dysplasia dietary habits (2). However, vitamin $\mathrm{C}$ and some carotenoids have been inversely associated with risk of gastric cancer (3). Catechins, for example, are major components of polyphenol in green tea, one of the most widely consumed beverages in Asia. Green tea catechins (GTCs) in particular possess various physiological effects such as antibacterial, anti-oxidative and anti-carcinogenic activities (4-6). However, epidemiological evidence of any anti-carcinogenic effects related to green tea consumption is still controversial. Although several casecontrol studies have reported that green tea consumption decreases the risk of gastric cancer (7-9), no inverse relationship between green tea consumption and the risk of gastric cancer has been observed in cohort studies (10-12).

The most abundant physiologically active constituent of GTCs is (-)-epigallocatechin-3-gallate (EGCG). The anticarcinogenic effects of EGCG have been extensively studied in many experimental systems, including the skin, lung, colon and prostate (13-16). This component appears to suppress cancer cell proliferation by inhibiting nuclear factor- $\kappa \mathrm{B}$, activator protein-1 and the epidermal growth factor receptor signal transduction pathway (17-19). Yamane et al (20) reported that EGCG suppresses cellular kinetics of the gastric mucosa in rat models of N-methyl-N'-nitro-nitrosoguanidine (MNNG)induced gastric cancer. Although the oral administration of EGCG in rodent models has shown an inhibitory effect on chemically-induced gastric tumorigenesis $(20,21)$, the molecular mechanism of protection has not been elucidated. Intestinal type gastric cancer occurs at later stages and undergoes relatively well-defined histological steps, including chronic atrophic gastritis, intestinal metaplasia and dysplasia (22). Hypergastrinemic insulin-gastrin (INS-GAS) mice mimic these human gastric carcinogenic sequences $(23,24)$. Although infection with HP accelerates gastric carcinogenesis in INS-GAS mice, uninfected male mice develop gastric cancer at around 20 months old regardless of the infection status (23). In the present study, we evaluated the effect of GTC supplementation on gastric carcinogenesis in INS-GAS mice in terms of gastric mucosal dysplasia.

\section{Materials and methods}

Materials. Polyphenon $60 \mathrm{~S}^{\circledR}$ was purchased from Mitsui Norin Co., Ltd., (Shizuoka, Japan) and contained $60.3 \%$ catechins, 
including EGCG (27.2\%), epicatechin gallate (7.7\%), epigallocatechin (15.2\%), epicatechin (6.8\%), gallocatechin gallate $(2.9 \%)$ and catechin gallate $(0.5 \%)$. The mixture was dissolved in distilled water at a concentration of $2,000 \mathrm{ppm}$.

Animals and the study design. Thirty-eight male INS-GAS mice from an $\mathrm{FVB} / \mathrm{N}$ background were used in the present study. The INS-GAS mice were supplied by the Massachusetts Institute of Technology (Boston, MA, USA) and bred at the Division of Laboratory Animal Resources at the University of Fukui. Animals were housed on hardwood bedding in a micro-isolator with solid-bottom polycarbonate cages and maintained at a constant temperature with a 12-h light/dark cycle. Mice were fed a regular chow diet (CLEA rodent diet CE-2; CLEA Japan, Inc., Tokyo, Japan) and provided distilled water ad libitum. At the age of 9 weeks, mice were divided into four groups: i) group 1, mice were supplemented with the GTC solution for 4 weeks ( $\mathrm{n}=8$ ); ii) group 2, the controls were given distilled water for 4 weeks $(\mathrm{n}=8)$; iii) group 3 , mice were supplemented with the GTC solution for 28 weeks $(n=13)$; and iv) group 4, the controls were given distilled water for 28 weeks $(n=9)$. All mice in groups 1 and 3 were given the GTC solution (2,000 ppm) instead of distilled water. The GTC solution and water were replaced weekly. There was no difference in the food consumption between the GTC-treated group and the control group in our preliminary experiment. After 4 or 28 weeks of GTC supplementation, at the age of 13 or 37 weeks, the mice were sacrificed by $\mathrm{CO}_{2}$ inhalation. Necropsy was performed under non-fasting conditions, and gastric tissue and serum samples were collected. All protocols were approved by the University of Fukui's Committee on Animal Care (permit no. 22047).

Histopathology and immunohistochemistry. During necropsy, linear strips of the stomach extending from the squamocolumnar junction through the proximal duodenum were fixed in $10 \%$ neutral buffered formalin overnight, processed routinely, paraffin-embedded, cut into $2-\mu \mathrm{m}$ sections, and stained with hematoxylin and eosin. Histological evaluation for inflammation and dysplasia were graded on an ascending scale from $0-4$ by a pathologist blinded to sample identity using previously outlined criteria (25). To evaluate cell proliferation of the gastric mucosa, 4 samples selected randomly from groups 3 and 4 were stained using Ki-67 immunohistochemistry. The slides were deparaffinized and hydrated in xylene and graded ethanol to water. The slides were incubated for $30 \mathrm{~min}$ with purified mouse anti-human Ki-67 monoclonal antibody (material no. 550609, dilution 1:50; BD Biosciences, San Diego, CA, USA) using the Vector M.O.M kit ImPRESS Peroxidase Polymer (Vector Laboratories, Inc., Burlingame, CA, USA) according to the manufacturer's instructions. After washing, the slides were incubated with diaminobenzidine for $5 \mathrm{~min}$ and counterstained with hematoxylin, dehydrated and mounted. The Ki-67 staining was evaluated by counting the number of positive nuclei per single gland, and the labeling index was expressed as the mean number of positively stained nuclei from 10 well-oriented glands as previously described (26).

Real-time reverse transcription polymerase chain reaction assay of cytokines. Total RNA was extracted from the corpus
Table I. Body weights (g) after supplementation of GTCs for 4 and 28 weeks.

Duration of GTCs administration

\begin{tabular}{lll}
\cline { 2 - 3 } Group & 4 weeks & 28 weeks \\
\hline Control & $34.7 \pm 0.7$ & $40.3 \pm 0.7$ \\
GTCs & $29.8 \pm 1.1^{\mathrm{a}}$ & $33.7 \pm 0.8^{\mathrm{a}}$ \\
\hline
\end{tabular}

${ }^{\mathrm{a}} \mathrm{P}<0.05$ compared with control INS-GAS mice.

of the stomach using TRI reagent (Sigma-Aldrich, St. Louis, MO, USA), according to the manufacturer's instructions. Total RNA ( $2 \mu \mathrm{g})$ was converted into complement (c)-DNA using a High-Capacity cDNA Archive kit (Applied Biosystems, Foster City, CA, USA), according to the manufacturer's protocol. Real-time quantitative polymerase chain reaction (PCR) was performed using StepOne Plus (Life Technologies, Carlsbad, CA, USA) under the following conditions: $50^{\circ} \mathrm{C}$ for $2 \mathrm{~min}$, $95^{\circ} \mathrm{C}$ for $10 \mathrm{~min}$ followed by 45 cycles at $95^{\circ} \mathrm{C}$ for $15 \mathrm{sec}$ and $60^{\circ} \mathrm{C}$ for $1 \mathrm{~min}$. The cDNA was amplified using the Real-Time PCR Master Mix (Toyobo, Osaka, Japan). The commercially available primer and probe mixes used in these experiments included interferon (IFN)- $\gamma$, tumor necrosis factor (TNF)- $\alpha$, interleukin (IL)-1 $\beta$, and glyceraldehyde-3-phosphate dehydrogenase (GAPDH) (Applied Biosystems). The PCR reaction was performed in duplicate, and the data were analyzed using a comparative cycle threshold method (27). The relative expression of the target gene was normalized to GAPDH and expressed as the fold change compared to an average value of the controls that were given distilled water for 4 weeks (group 2).

Serum gastrin levels. The blood samples at necropsy were centrifuged and stored at $-20^{\circ} \mathrm{C}$. Serum gastrin levels in groups 3 and 4 were measured using a radioimmunoassay (BML Corp., Tokyo, Japan).

Statistical analysis. Non-parametric data, including two histological parameters and gene expression assays, were analyzed using Mann-Whitney U test. Parametric data, including body weight, the serum gastrin level, and Ki-67 labeling were analyzed using Student's t-test. Statistical computing was performed using Prism 6 software for Windows (Graphpad Software, Inc., San Diego, CA, USA). Data are shown as mean \pm standard error of mean. Statistical significance was defined as a P-value $<0.05$.

\section{Results}

Administration of GTCs decreased body weights and serum gastrin levels. We compared body weights between the GTC-administered group and the control group to confirm that GTCs were reliably administered at a sufficient dosage. In groups 1 and 2, for which the duration of administration was 4 weeks, the body weight was significantly lower in the group receiving GTCs $(29.8 \pm 1.1 \mathrm{~g})$ than in the control group $(34.7 \pm 0.7 \mathrm{~g})$. Similarly, in groups 3 and 4 , for which the dura- 
A

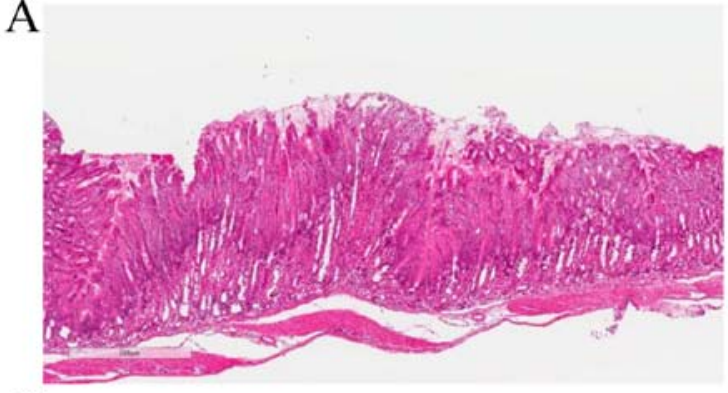

$\mathrm{C}$
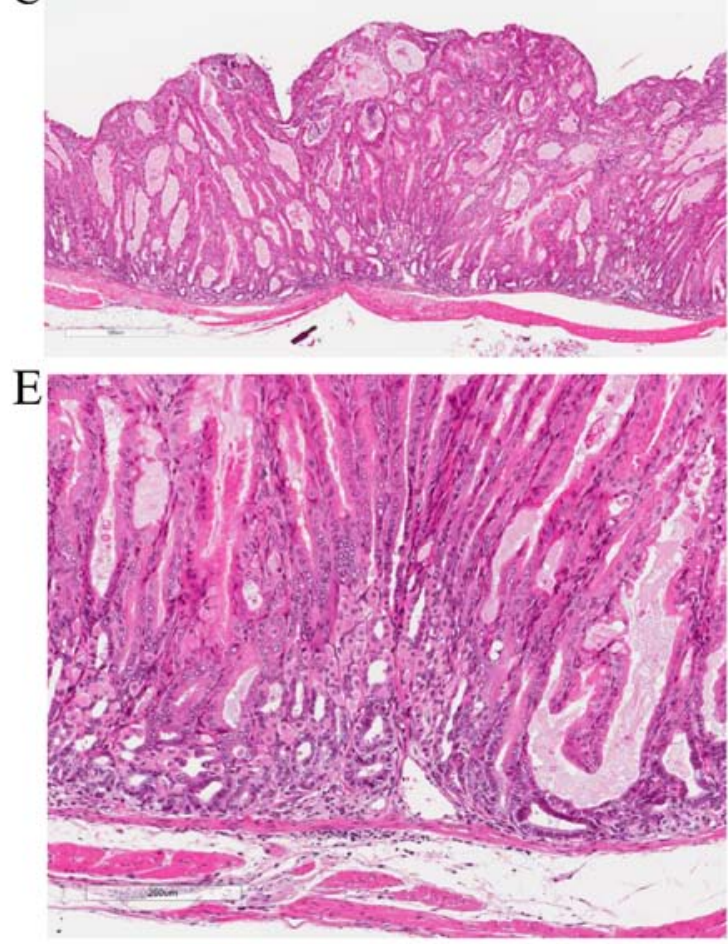

$\mathrm{B}$

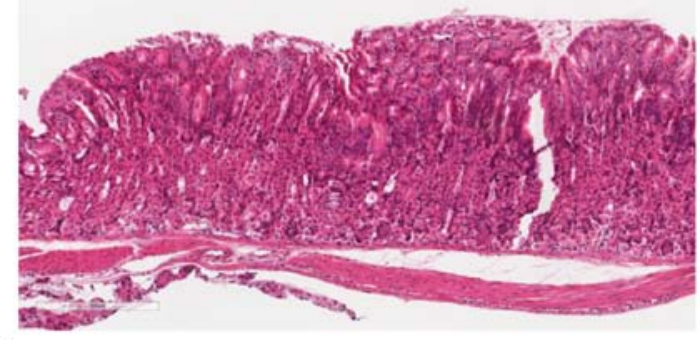

$\mathrm{D}$
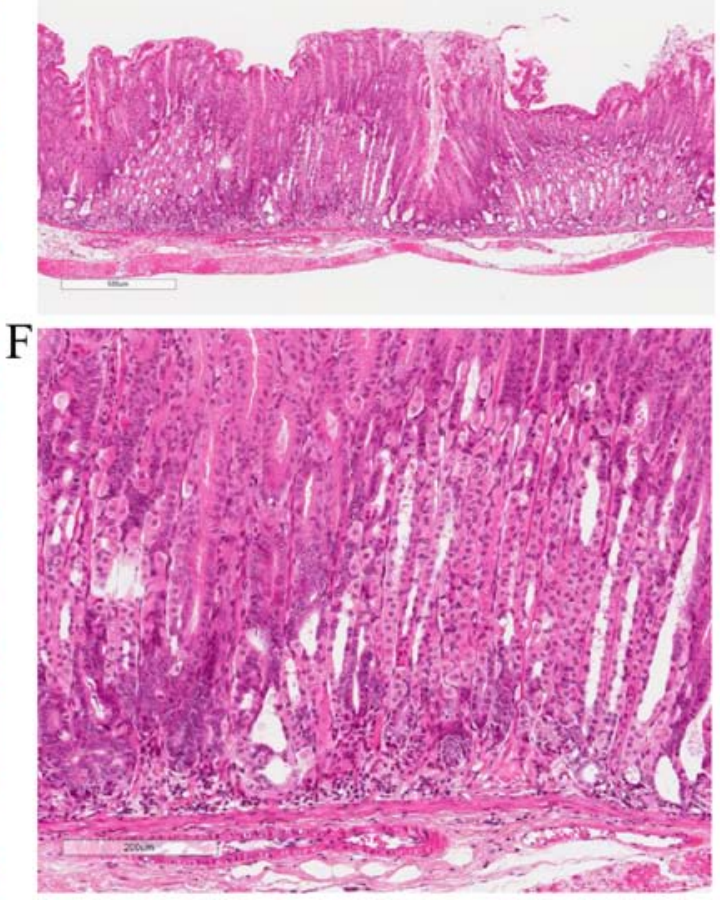

Figure 1. Histopathology of the corpus of the stomach in insulin-gastrin mice. (A) Mice after sham supplementation for 4 weeks. (B) Mice after 4 weeks of green tea catechin (GTC) supplementation. (C and E) Mice after 28 weeks of sham supplementation; the glands have a tortuous architecture. (D and F) Less severe mucosal change was noted in the GTC-supplemented mice after 28 weeks.

tion of administration was 28 weeks, the body weight was significantly lower in the group receiving GTCs $(33.7 \pm 0.8 \mathrm{~g})$ than in the control group $(40.3 \pm 0.7 \mathrm{~g}$ ) (Table I). Furthermore, when the serum gastrin levels were compared between the 28-week GTC-administered group and control groups, the level of gastrin $(863 \pm 65.6 \mathrm{pg} / \mathrm{ml})$ was significantly lower in the GTC-administered group than in the control group $(1,912 \pm 507.4 \mathrm{pg} / \mathrm{ml})(\mathrm{P} \leq 0.05)$. The low gastrin level in the GTC-administered group during non-fasting states indicated that the gastrin level was continuously suppressed by the administration of GTCs.

Administration of GTCs attenuated gastric dysplasia. To evaluate the effects of GTC administration on gastritis, we performed histopathological examinations of the gastric mucosa. The mice developed minimal to mild corpus gastritis. Similar to the results of previous studies using INS-GAS mice $(23,24,26)$, atrophy of the gastric fundic gland, hyperplasia of the glandular epithelium, and intestinal epithelium metaplasia and dysplasia were observed (Fig. 1). No differences in inflammation scores were observed between the GTC-administered group and the control group in either the 4-week or the 28-week administration clusters. In the 4-week groups, no differences in the dysplasia scores were observed between the GTC-administered group and the control group. However, the dysplasia score was significantly lower in the 28 -week GTC-administered group than in the 28-week control group (Fig. 2). These results suggested that although INS-GAS mice inevitably slowly develop gastric cancer from gastritis regardless of the intervention, the progression of gastric mucosal dysplasia was inhibited by long-term GTC administration.

GTCs modulated IFN- $\gamma$ expression in the gastric mucosa. To molecularly evaluate the mechanism of changes in dysplasia, we analyzed messenger (m)-RNA expression of inflammatory cytokines such as IFN- $\gamma$, TNF- $\alpha$ and IL- $1 \beta$ in the gastric tissue (Fig. 3). In the 4-week administration cluster, mRNA levels of IFN- $\gamma$ were significantly lower in the GTC-administered group than in the control group $(\mathrm{P} \leq 0.05)$. In addition, although not significantly different, the 28 -week mRNA levels of IFN- $\gamma$ were also lower in the GTC-administered group than in the control group $(\mathrm{P}=0.056)$. We also analyzed the mRNA expres- 

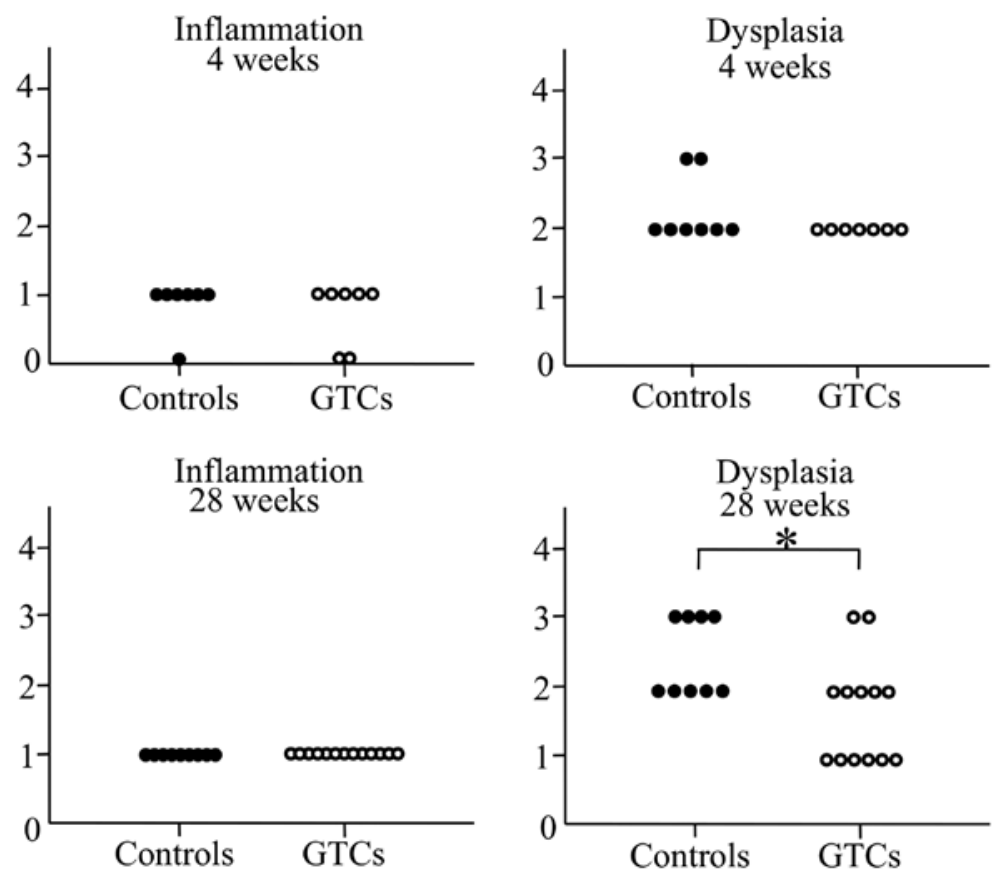

Figure 2. Gastric histological scores of intact and green tea catechin (GTC)-supplemented insulin-gastrin mice for 4 and 28 weeks. "P $\leq 0.05$ compared with intact mice.
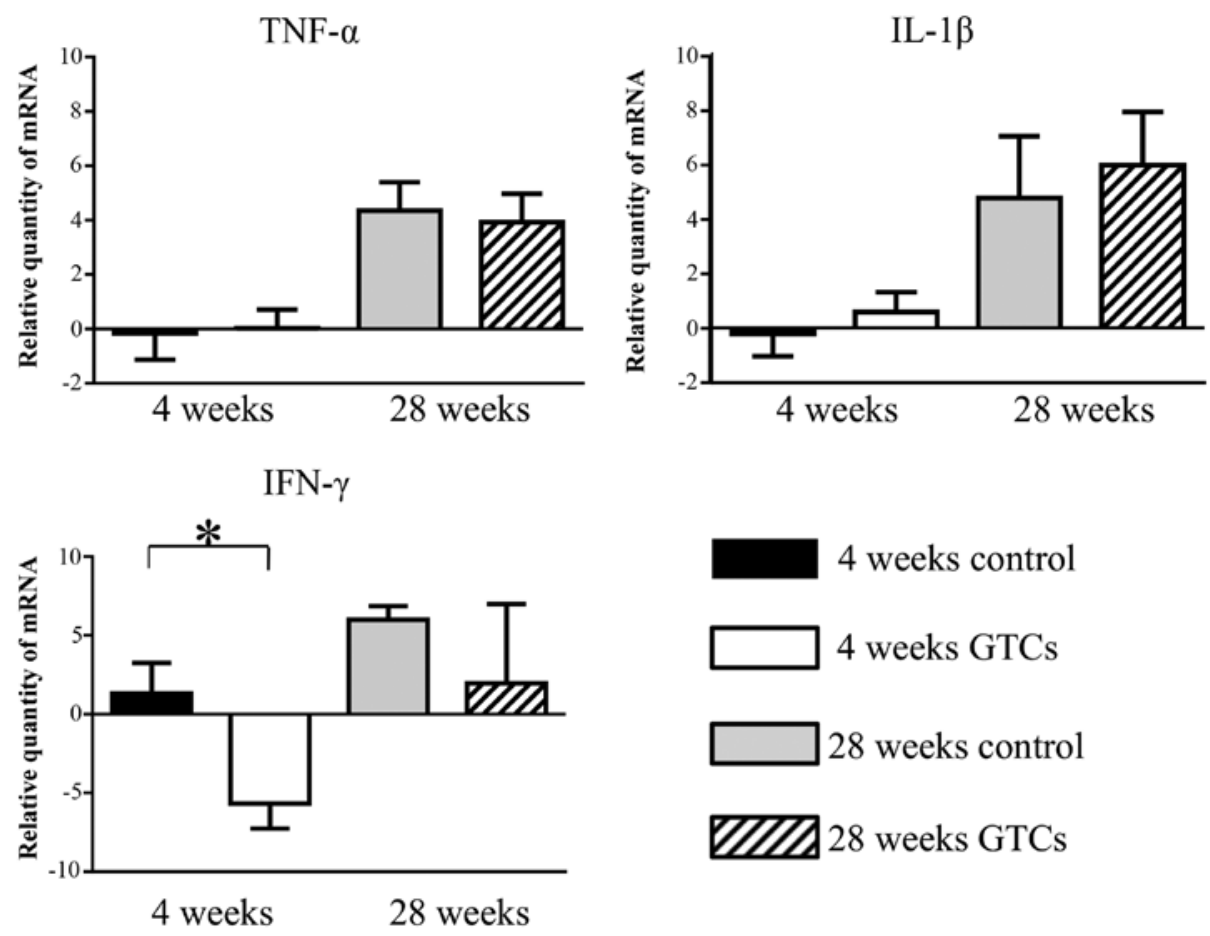

Figure 3. Gastric tissue messenger RNA levels of pro-inflammatory cytokines. Gastric tissues were evaluated using quantitative polymerase chain reaction for messenger (m)-RNA levels of interferon (IFN)- $\gamma$, tumor necrosis factor (TNF)- $\alpha$ and interleukin (IL)- $1 \beta$. The target gene mRNAs were normalized to that of glyceraldehyde-3-phosphate dehydrogenase. Data are expressed as the mean median fold change normalized to the average of the intact insulin-gastrin (INS-GAS) mice after sham supplementation for 4 weeks. "P $\leq 0.05$ compared with intact INS-GAS mice.

sion of TNF- $\alpha$ and IL-1 $\beta$, but no significant differences were observed between the GTC-administered group and the control group in either the 4-week or 28-week administration clusters. These results suggested that the expression of IFN- $\gamma$ in the gastric mucosa was inhibited by GTC administration, but GTC administration had little or no effect on the expression of other inflammatory cytokines such as TNF- $\alpha$ and IL-1 $\beta$.

Administration of GTCs suppressed epithelial cell proliferation in the gastric mucosa. To evaluate the effect of GTC 


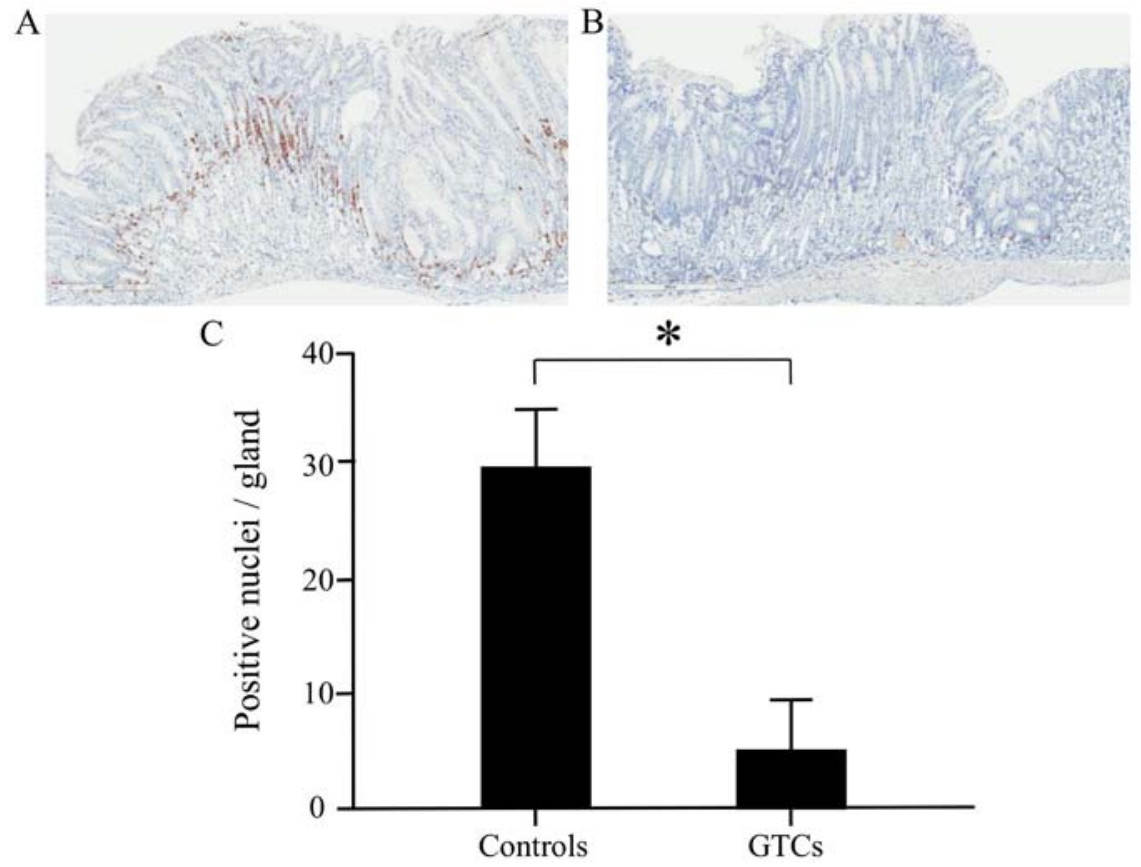

Figure 4. Immunohistochemical detection of Ki-67 in the proximal corpus of the stomach. Green tea catechin (GTC)-supplemented mice showed significantly decreased Ki-67 labeling index (LI) compared with intact mice. (A) Mice after sham supplementation for 28 weeks. (B) Mice after GTC supplementation for 28 weeks. (C) Epithelial cell proliferation LI of the proximal corpus. ${ }^{*} \mathrm{P} \leq 0.05$.

administration on cell proliferation in the gastric mucosal epithelium, analysis was performed in the 28 -week administration cluster using the Ki-67 immunohistochemical staining labeling index. We observed Ki-67 positive nuclei from the glandular cervical region to the crypt epithelium (Fig. 4A and B). The labeling index of Ki-67 was significantly lower in the GTC-administered group than in the control group (Fig. 4C). This result suggested that cell growth in the gastric mucosal epithelium was inhibited by GTC administration.

\section{Discussion}

In the present study, we analyzed the preventive effects of GTC administration on gastric cancer using a mouse model. INS-GAS mice exhibit high gastrin levels and gastric fundic gland atrophy, and develop gastric cancer after approximately 20 months in their natural life cycle (23). In the present study, we observed a significant reduction in body weight due to GTC administration at 4 and 28 weeks, and suppressed gastric mucosa dysplasia progression after 28 weeks, suggesting a tumor-inhibitory effect from GTCs. Furthermore, GTC administration also appeared to suppress mRNA expression of IFN- $\gamma$ in the gastric mucosa and proliferation of gastric mucosal epithelial cells.

GTCs have been reported to show various physiological activities such as antibacterial, antitumor and anti-inflammatory actions (4-6). In the present study, the GTC-administered groups had a significant reduction in body weight compared to the control groups, which is in agreement with previous reports on abdominal cavity fat and overall weight reduction following green tea powder administration in mice (28). The suggested mechanisms involve GTC-suppressed fatty acid synthase activity in the liver, increased activity of the enzymes involved in lipolysis (29), and increased expression of lipolytic enzymes in adipocytes (30). In addition, the catechin intake and exercise have been reported to have inhibitory effects on the increase in mouse body weight (31). In the present study, GTCs administered via drinking water showed sufficient physiological activity to result in body weight reduction.

In the 28-week administration cluster, the serum gastrin level was significantly lower in the GTC group than in the control group. Gastric fundic gland atrophy and the reduction of the gastric acid secretion capacity are seen in INS-GAS mice as early as 6 months after birth in their natural life cycle, and further increases in the gastrin levels are inevitably observed as time progresses (23). Sato et al (32) reported that GTC administration reduces the serum gastrin level and protects against stress-initiated acute gastric mucosal damage in water-immersion mouse models. Furthermore, gastrin and histamine receptor antagonists reportedly suppress the progression of gastric mucosal atrophy due to chronic gastritis in Helicobacter felis-infected INS-GAS mice, ultimately resulting in the suppression of gastric carcinogenesis (27). The mechanism by which GTCs reduce gastrin levels in INS-GAS mice is not fully understood, but it is thought that the reduction inhibits the progression of dysplasia in the gastric mucosa. The present study supported this hypothesis, as dysplasia of the gastric mucosa was indeed significantly suppressed in the 28-week GTC-administered group compared to the control group.

The GTC-administered group also had reduced gastric mucosal IFN- $\gamma$ expression, suggesting that IFN- $\gamma$ is involved in the suppression of dysplasia. An HP infection is a class I gastric carcinogen; the infection causes chronic gastritis, which progresses into atrophic gastritis, intestinal metaplasia, and dysplasia and ultimately leads to carcinogenesis (22). Increased expressions of inflammatory cytokines such as IFN- $\gamma$ and IL-1 $\beta$ are seen in HP-infected gastric mucosa, rein- 
forcing their important role in inflammatory carcinogenesis $(33,34)$. Furthermore, IFN- $\gamma$ knockout mice fail to develop HP-infected gastritis or gastric mucosa atrophy (35). In this study, gastric mucosal IFN- $\gamma$ expression was suppressed by GTC administration at 4 weeks, and although the difference did not remain significant at 28 weeks, a reduction was still noticeable. To date, GTC administration has been reported to inhibit the local production of inflammatory cytokines such as IFN- $\gamma$ and TNF- $\alpha$ in mouse models with dextran sulfate sodium-induced colitis, autoimmune hepatitis and arthritis (36-38). In addition, it is reported that GTC decrease IL-1 $\beta$ expression in melanoma cells (39). The inhibitory effect of GTC on mRNA expression of IL- $1 \beta$ and TNF- $\alpha$ was not observed in this study. Host factor may be associated with the differences in susceptibility to GTC.

In the present study, the inhibition of cell proliferation of the gastric mucosal epithelium was observed in the GTC-administered groups, similar to the GTC-induced growth inhibitory effects of gastric mucosal epithelial cells in an MNNG-induced gastric carcinogenesis model. Many studies have thus far reported cytostatic effects of GTC in various cancer cell lines such as lung, breast and colorectal cancer (40-42), which are thought to involve TNF- $\alpha$ release inhibition and an inhibitory effect on DNA methylation. Some mechanisms have been proposed for the effect of GTCs on cell proliferation. GTC induces apoptosis, cell cycle arrest and modulation intracellular cell signaling. EGCG trigger cell growth arrest pathway at G1 stage cycle through regulation of cyclin D1, cdk4, cdk6, p21/WAF1/CIP1 and p27/KIP1 and induced apoptosis through caspase- 3 and caspase- 9 activation (43). Furthermore, cell growth inhibition and apoptosis induction by EGCG have been identified in gastric carcinoma cell lines as well. These mechanisms involve Id1 and EGCGregulated surviving expression, but the specifics of these mechanisms have not yet been elucidated $(44,45)$.

We reported the potential preventive effects of GTCs on gastric carcinogenesis in INS-GAS mice via the suppression of IFN- $\gamma$ expression and gastric mucosal epithelial cell growth inhibition. In addition, GTCs possess anti-oxidant and antivascularity effects, which should be equally closely examined in future studies. Understanding the protective mechanisms of GTCs against gastric carcinogenesis at a molecular level may lead to new therapeutic and preventative interventions for treating gastric cancer in humans.

\section{Acknowledgements}

The INS-GAS mice were supplied by Professor James G. Fox (Massachusetts Institute of Technology). We would like to thank Editage (www.editage.jp) for English language editing. The present study was supported by the JSPS Grant-in-Aid for Scientific Research (C) (grant no. 23510346).

\section{References}

1. Ferro A, Peleteiro B, Malvezzi M, Bosetti C, Bertuccio P, Levi F, Negri E, La Vecchia $C$ and Lunet N: Worldwide trends in gastric cancer mortality (1980-2011), with predictions to 2015, and incidence by subtype. Eur J Cancer 50: 1330-1344, 2014.

2. Parkin DM, Bray F, Ferlay J and Pisani P: Global cancer statistics, 2002. CA Cancer J Clin 55: 74-108, 2005.
3. Gonzalez CA and Riboli E: Diet and cancer prevention: Contributions from the European Prospective Investigation into Cancer and Nutrition (EPIC) study. Eur J Cancer 46: 2555-2562, 2010.

4. Shiota S, Shimizu M, Mizushima T, Ito H, Hatano T, Yoshida T and Tsuchiya T: Marked reduction in the minimum inhibitory concentration (MIC) of beta-lactams in methicillin-resistant Staphylococcus aureus produced by epicatechin gallate, an ingredient of green tea (Camellia sinensis). Biol Pharm Bull 22: 1388-1390, 1999.

5. El-Beshbishy HA: Hepatoprotective effect of green tea (Camellia sinensis) extract against tamoxifen-induced liver injury in rats. J Biochem Mol Biol 38: 563-570, 2005.

6. Cheng CW, Shieh PC, Lin YC, Chen YJ, Lin YH, Kuo DH, Liu JY, Kao JY, Kao MC and Way TD: Indoleamine 2,3-dioxygenase, an immunomodulatory protein, is suppressed by (-)-epigallocatechin-3-gallate via blocking of gamma-interferoninduced JAK-PKC-delta-STAT1 signaling in human oral cancer cells. J Agric Food Chem 58: 887-894, 2010.

7. Kono S, Ikeda M, Tokudome S and Kuratsune M: A case-control study of gastric cancer and diet in northern Kyushu, Japan. Jpn J Cancer Res 79: 1067-1074, 1988.

8. Ji BT, Chow WH, Yang G, McLaughlin JK, Gao RN, Zheng W, Shu XO, Jin F, Fraumeni JF Jr and Gao YT: The influence of cigarette smoking, alcohol, and green tea consumption on the risk of carcinoma of the cardia and distal stomach in Shanghai, China. Cancer 77: 2449-2457, 1996.

9. Inoue M, Tajima K, Hirose K, Hamajima N, Takezaki T, Kuroishi T and Tominaga S: Tea and coffee consumption and the risk of digestive tract cancers: Data from a comparative casereferent study in Japan. Cancer Causes Control 9: 209-216, 1998.

10. Tsubono Y, Nishino Y, Komatsu S, Hsieh CC, Kanemura S, Tsuji I, Nakatsuka H, Fukao A, Satoh H and Hisamichi S: Green tea and the risk of gastric cancer in Japan. N Engl J Med 344: 632-636, 2001.

11. Nagano J, Kono S, Preston DL and Mabuchi K: A prospective study of green tea consumption and cancer incidence, Hiroshima and Nagasaki (Japan). Cancer Causes Control 12: 501-508, 2001.

12. Hoshiyama Y, Kawaguchi T, Miura Y, Mizoue T, Tokui N, Yatsuya H, Sakata K, Kondo T, Kikuchi S, Toyoshima H, et al; Japan Collaborative Cohort Study Group: A prospective study of stomach cancer death in relation to green tea consumption in Japan. Br J Cancer 87: 309-313, 2002.

13. Singh T and Katiyar SK: Green tea polyphenol, (-)-epigallocatechin-3-gallate, induces toxicity in human skin cancer cells by targeting $\beta$-catenin signaling. Toxicol Appl Pharmacol 273: 418-424, 2013.

14. Wang H, Bian S and Yang CS: Green tea polyphenol EGCG suppresses lung cancer cell growth through upregulating miR-210 expression caused by stabilizing HIF-1 $\alpha$. Carcinogenesis 32 : 1881-1889, 2011.

15. Baek SJ, Kim JS, Jackson FR, Eling TE, McEntee MF and Lee SH: Epicatechin gallate-induced expression of NAG-1 is associated with growth inhibition and apoptosis in colon cancer cells. Carcinogenesis 25: 2425-2432, 2004.

16. Harper CE, Patel BB, Wang J, Eltoum IA and Lamartiniere CA: Epigallocatechin-3-gallate suppresses early stage, but not late stage prostate cancer in TRAMP mice: Mechanisms of action. Prostate 67: 1576-1589, 2007.

17. Ahmad N, Gupta S and Mukhtar H: Green tea polyphenol epigallocatechin-3-gallate differentially modulates nuclear factor kappaB in cancer cells versus normal cells. Arch Biochem Biophys 376: 338-346, 2000.

18. Dong Z, Ma W, Huang C and Yang CS: Inhibition of tumor promoter-induced activator protein 1 activation and cell transformation by tea polyphenols, (-)-epigallocatechin gallate, and theaflavins. Cancer Res 57: 4414-4419, 1997.

19. Adachi S, Shimizu M, Shirakami Y, Yamauchi J, Natsume H, Matsushima-Nishiwaki R, To S, Weinstein IB, Moriwaki H and Kozawa O: (-)-Epigallocatechin gallate downregulates EGF receptor via phosphorylation at Ser1046/1047 by p38 MAPK in colon cancer cells. Carcinogenesis 30: 1544-1552, 2009.

20. Yamane T, Takahashi T, Kuwata K, Oya K, Inagake M, Kitao Y, Suganuma $\mathrm{M}$ and Fujiki H: Inhibition of N-methyl-N'-nitro-Nnitrosoguanidine-induced carcinogenesis by (-)-epigallocatechin gallate in the rat glandular stomach. Cancer Res 55: 2081-2084, 1995. 
21. Katiyar SK, Agarwal R, Zaim MT and Mukhtar H: Protection against $\mathrm{N}$-nitrosodiethylamine and benzo[a]pyrene-induced forestomach and lung tumorigenesis in $\mathrm{A} / \mathrm{J}$ mice by green tea. Carcinogenesis 14: 849-855, 1993.

22. Correa P: Human gastric carcinogenesis: A multistep and multifactorial process - First American Cancer Society Award Lecture on Cancer Epidemiology and Prevention. Cancer Res 52: 6735-6740, 1992.

23. Wang TC, Dangler CA, Chen D, Goldenring JR, Koh T, Raychowdhury R, Coffey RJ, Ito S, Varro A, Dockray GJ, et al: Synergistic interaction between hypergastrinemia and Helicobacter infection in a mouse model of gastric cancer. Gastroenterology 118: 36-47, 2000.

24. Fox JG, Wang TC, Rogers AB, Poutahidis T, Ge Z, Taylor N, Dangler CA, Israel DA, Krishna U, Gaus K, et al: Host and microbial constituents influence Helicobacter pylori-induced cancer in a murine model of hypergastrinemia. Gastroenterology 124: 1879-1890, 2003.

25. Rogers AB, Taylor NS, Whary MT, Stefanich ED, Wang TC and Fox JG: Helicobacter pylori but not high salt induces gastric intraepithelial neoplasia in B6129 mice. Cancer Res 65: 10709-10715, 2005.

26. Ohtani M, García A, Rogers AB, Ge Z, Taylor NS, Xu S, Watanabe K, Marini RP, Whary MT, Wang TC, et al: Protective role of 17 beta -estradiol against the development of Helicobacter pylori-induced gastric cancer in INS-GAS mice. Carcinogenesis 28: 2597-2604, 2007.

27. Takaishi S, Cui G, Frederick DM, Carlson JE, Houghton J, Varro A, Dockray GJ, Ge Z, Whary MT, Rogers AB, et al: Synergistic inhibitory effects of gastrin and histamine receptor antagonists on Helicobacter-induced gastric cancer. Gastroenterology 128: 1965-1983, 2005.

28. Sayama K, Lin S, Zheng G and Oguni I: Effects of green tea on growth, food utilization and lipid metabolism in mice. In Vivo 14: 481-484, 2000

29. Sugiura C, Nishimatsu S, Moriyama T, Ozasa S, Kawada T and Sayama K: Catechins and caffeine inhibit fat accumulation in mice through the improvement of hepatic lipid metabolism. J Obes 2012: 520510, 2012

30. Lee MS, Kim CT, Kim IH and Kim Y: Inhibitory effects of green tea catechin on the lipid accumulation in 3T3-L1 adipocytes Phytother Res 23: 1088-1091, 2009.

31. Murase T, Haramizu S, Shimotoyodome A and Tokimitsu I: Reduction of diet-induced obesity by a combination of teacatechin intake and regular swimming. Int J Obes 30: 561-568, 2006.

32. Sato H, Matsui T and Arakawa Y: The protective effect of catechin on gastric mucosal lesions in rats, and its hormonal mechanisms. J Gastroenterol 37: 106-111, 2002.

33. Sayi A, Kohler E, Hitzler I, Arnold I, Schwendener R, Rehrauer H and Müller A: The $\mathrm{CD}^{+}{ }^{+} \mathrm{T}$ cell-mediated IFN-gamma response to Helicobacter infection is essential for clearance and determines gastric cancer risk. J Immunol 182: 7085-7101, 2009.
34. Uedo N, Tatsuta M, Iishi H, Baba M, Yano H, Ishihara R, Higashino $\mathrm{K}$ and Ishiguro S: Enhancement by interleukin-1 beta of gastric carcinogenesis induced by N-methyl-N'-nitro$\mathrm{N}$-nitrosoguanidine in Wistar rats: A possible mechanism for Helicobacter pylori-associated gastric carcinogenesis. Cancer Lett 198: 161-168, 2003.

35. Smythies LE, Waites KB, Lindsey JR, Harris PR, Ghiara P and Smith PD: Helicobacter pylori-induced mucosal inflammation is Th1 mediated and exacerbated in IL-4, but not IFN-gamma, gene-deficient mice. J Immunol 165: 1022-1029, 2000.

36. Shirakami Y, Shimizu M, Tsurumi H, Hara Y, Tanaka T and Moriwaki H: EGCG and polyphenon E attenuate inflammationrelated mouse colon carcinogenesis induced by AOM plus DDS. Mol Med Rep 1: 355-361, 2008.

37. Haqqi TM, Anthony DD, Gupta S, Ahmad N, Lee MS, Kumar GK and Mukhtar H: Prevention of collagen-induced arthritis in mice by a polyphenolic fraction from green tea. Proc Natl Acad Sci USA 96: 4524-4529, 1999.

38. Wang Y, Mei Y, Feng D and Xu L: (-)-Epigallocatechin-3-gallate protects mice from concanavalin A-induced hepatitis through suppressing immune-mediated liver injury. Clin Exp Immunol 145: 485-492, 2006.

39. Ellis LZ, Liu W, Luo Y, Okamoto M, Qu D, Dunn JH and Fujita M: Green tea polyphenol epigallocatechin-3-gallate suppresses melanoma growth by inhibiting inflammasome and IL-1 $\beta$ secretion. Biochem Biophys Res Commun 414: 551-556, 2011.

40. Fujiki H, Suganuma M, Okabe S, Sueoka N, Komori A, Sueoka E, Kozu T, Tada Y, Suga K, Imai K, et al: Cancer inhibition by green tea. Mutat Res 402: 307-310, 1998.

41. Deguchi H, Fujii T, Nakagawa S, Koga T and Shirouzu K: Analysis of cell growth inhibitory effects of catechin through MAPK in human breast cancer cell line T47D. Int J Oncol 21: 1301-1305, 2002.

42. Moseley VR, Morris J, Knackstedt RW and Wargovich MJ: Green tea polyphenol epigallocatechin 3-gallate, contributes to the degradation of DNMT3A and HDAC3 in HCT 116 human colon cancer cells. Anticancer Res 33: 5325-5333, 2013.

43. Shankar S, Suthakar G and Srivastava RK: Epigallocatechin3 -gallate inhibits cell cycle and induces apoptosis in pancreatic cancer. Front Biosci 12: 5039-5051, 2007.

44. Ma J, Shi M, Li G, Wang N, Wei J, Wang T, Ma J and Wang Y: Regulation of Id 1 expression by epigallocatechin-3-gallate and its effect on the proliferation and apoptosis of poorly differentiated AGS gastric cancer cells. Int J Oncol 43: 1052-1058, 2013.

45. Onoda C, Kuribayashi K, Nirasawa S, Tsuji N, Tanaka M, Kobayashi D and Watanabe N: (-)-Epigallocatechin-3-gallate induces apoptosis in gastric cancer cell lines by down-regulating survivin expression. Int J Oncol 38: 1403-1408, 2011. 